\title{
Interactive ludic Activities for Elderly Persons in a Long-Stay Institution
}

\author{
${ }^{1}$ Nathalie Porfirio Mendes, ${ }^{2}$ Vanessa Kelly Cardoso Estumano, ${ }^{3}$ Gilvana de Carvalho Moraes, ${ }^{4}$ Cleise Ellen \\ Ferreira Pantoja, ${ }^{5}$ Miquéias Farias Rodrigues, ${ }^{6}$ Anna Clara Damasceno Jardim, ${ }^{7}$ Gyselle Morais da Silva, \\ ${ }^{8}$ Rafael Oliveira Teixeira, ${ }^{9}$ Juliane Conceição Costa Ribeiro, ${ }^{10}$ Clarissa Porfirio Mendes, ${ }^{11}$ Hallessa de Fátima \\ da Silva Pimentel, ${ }^{12}$ Milene de Andrade Gouvêa Tyll, ${ }^{13}$ Renata Glaucia Barros da Silva Lopes, ${ }^{14}$ Glenda \\ Roberta Oliveira Naiff Ferreira, ${ }^{15}$ Tássio Ricardo Martins da Costa*, ${ }^{16}$ Maicon de Araujo Nogueira
}

${ }^{1}$ Nurse. Master's Degree in Nursing, Federal University of Para (UFPA), Professor at Amazon University (UNAMA), Belem, Para, Brazil.

${ }^{2}$ Nurse. Amazon University (UNAMA), Belem, Para, Brazil.

${ }^{3}$ Nurse. Amazon University (UNAMA), Belem, Para, Brazil.

${ }^{4}$ Nurse. Amazon University (UNAMA), Belem, Para, Brazil.

${ }^{5}$ Nursing Undergraduate at Amazon University (UNAMA), Belem, Para, Brazil.

${ }^{6}$ Nursing Undergraduate at Amazon University (UNAMA), Belem, Para, Brazil.

${ }^{7}$ Amazon University (UNAMA), Belem, Para, Brazil.

${ }^{8}$ Pharmacy Student at Amazon University (UNAMA), Belem, Para, Brazil.

${ }^{9}$ Nurse. Amazon University (UNAMA), Belem, Para, Brazil.

${ }^{10}$ Nurse. Master's Degree in Nursing, Federal University of Para (UFPA), Nurse at Ophir Loyola Hospital. Belem, Para, Brazil.

${ }^{11}$ Nurse. Master's Degree in Collective Health - PPGSAS/UFPA, Professor at Amazon University (UNAMA), Belem, Para, Brazil.

${ }^{12}$ Nurse. Doctorate Degree Student in Education and Health Sciences. Master's Degree in Enviromental Science and Health PUC/Goias. Professor at Amazon

University. Nurse at Coronary unit of the Gaspar Vianna clinic hospital. Belem. Para. Brazil.

${ }^{13}$ Nurse. Master in epidemiology, Federal University of Para (UFPA), Professor at University of Amazonia (UNAMA), Belem, Para, Brazil.

${ }^{14}$ Nurse. PhD in Biology of Infectious and Parasitic Agents, Federal State University. Professor at Federal University of Para (UFPA), Belem, Para, Brazil.

${ }^{15^{*}}$ Nurse. University of Para State (UEPA), Belem, Para, Brazil.

${ }^{16}$ Nurse. Master's Degree in Health Education, Para State University (UEPA). Professor at Amazon University (UNAMA), Belem, Para, Brazil.

Correspondence Author: Tássio Ricardo Martins da Costa, Nurse. University of Para State (UEPA), Belem, Para, Brazil

E-mail: tassioricardocosta@gmail.com

Received date: 28 January 2019, Accepted date: 13 March 2018, Online date: 28 March 2019

Copyright: (C) 2019 Nathalie Porfirio Mendes et al, This is an open-access article distributed under the terms of the Creative Commons Attribution License, which permits unrestricted use, distribution, and reproduction in any medium, provided the original author and source are credited.

\begin{abstract}
The state and the private market share the responsibilities of caring for the elderly with families. In this context, they are an alternative form of non-family care, Long-Term Care Institutions for the Elderly (ILPI), whether public or private. In this context, the objective of this study is to stimulate the development of social interaction activities among people living in a Long Stay Institution for the Elderly. Therefore, a qualitative, convergent study was carried out in the Community of Long-Term Care Institutions for the Elderly (ILPI), in Belém, northern Brazil, once a week, on Mondays, lasting 3 hours daily. Included in this study were elderly men, mean age 62.7 years, who performed approximately seven months of play activities that aimed to improve the autonomy of daily life activities, stimulating attention, memory, identity recovery and social interaction. The elderly was motivated and made available the activities proposed by the group, actively participating in all activities with enthusiasm. These activities were elaborated and performed at the ILPI, were in fact feasible to promote the health of the elderly, based on the postulates that support the strategies of play activities, considering the epidemiological and cultural reality of the elderly involved. In addition, we observed that play activities emerge as a technology that favors gerontological appropriation and is an adequate proposal to promote elderly health, since it provides a climate of motivation, interaction, relaxation and bonding (elderly-elderly, elderly-extensionist) and behavioral, becoming a facilitating tool for the care and promotion of active and healthy aging. Therefore, play activities are of great relevance for use with the elderly, and when used in ILPI are directly related to the health promotion of this population, providing very benefits. These benefits were evident during the performance of activities, such as interpersonal interaction, activation of cognitive and motivation. Therefore, the importance of the use of play strategies as a tool to promote improvements in the quality of life of institutionalized elderly people and the promotion of active and healthy aging should be reiterated.
\end{abstract}

Key words: Aged. Homes for the Aged. Elderly Health. Healthy Aging. 


\section{INTRODUCTION}

Population aging is considered a natural, gradual and dynamic process, where morphological, psychological, functional and biochemical changes occur that may decrease the individual's adaptive capacity towards the environment, making them vulnerable to chronic diseases (Santos-Orlandi et al. 2017).

Aging brings changes in the social, cultural, economic, institutional, value system and family arrangements. As a result, the state and the private market share the responsibilities of caring for the elderly with families. In this context, they are an alternative form of non-family care, Long-Term Care Institutions for the Elderly (ILPI), whether public or private (Silva, 2016).

According to resolution 283/2005, created by the National Sanitary Surveillance Agency (ANVISA), ILPI are governmental or non-governmental institutions of a residential character intended for the collective residence of persons 60 years of age and over, with or without family support in condition freedom, dignity and citizenship. Historically, its origin is related to asylums and to the welfare profile, with care initially directed to the needy population that needed shelter, fruits of Christian charity in the absence of public policies (Camarano, 2016).

Aging causes a progressive decrease in the functional capacity of individuals - senescence -, a peculiar phase of life that is not characterized as pathological. However, conditions of overload, such as illness, accidents and emotional stress, as well as unfavorable socio-sanitary conditions, can lead to a pathological state - senility - demanding complex life and health care. The possibilities for surviving the limitations can be avoided or delayed if professionals and society in general work together, seeking strategies for a healthier life, with the incorporation of more favorable attitudes and behaviors to improve the quality of life in the process of aging (Costa et al. 2017).

Among the activities available to the elderly, activities that promote meaningful learning and social interaction, as well as changes in daily habits and health awareness are highlighted (Cyrino et al. 2016).

Therefore, it is essential to emphasize the importance of adequate training and motivation of health professionals and care givers to increase the interaction of these elderly, making activities more enjoyable and productive (Fuentes et al. 2014). In view of the above, the main objective of this study is to stimulate the development of social interaction activities among elderly people living in long-term care facilities for the elderly.

\subsection{Study Design}

\section{METHOD}

A qualitative study based on an extension program through a transdisciplinary action of Nursing, Physical Therapy and Pharmacy students, which used the Convergent Care Research (PCA) method for the purpose to stimulate the development of social interaction activities among people living in a Long Stay Institution for the Elderly with a view to promoting and cultivating a healthy and active aging (Trentini; Paim and Silva, 2014).

\subsection{Data Collection and Consent}

Data collection took place from the ILPI activities that went through four interrelated phases, as described: 1) Recognition phase: marked by the initial invitation to participate in the group and care to provide space for the meetings. 2) Dissemination Phase: includes the externalization of the expectations, desires, feelings, needs, aspirations and opinions of the groups, when it is time to meet the elderly, including their tastes and desires, their potentialities and limitations. 3) Distribution phase: it was the exchange of experiences of the research participants with the extension agents. 4) Phase of the rethink: it is formed in the reflection of the group on the work developed, when the participants present the advantages, disadvantages and suggestions for future work (Trentini; and Paim and Silva, 2014).

Following the legal and ethical parameters, the legal representative for the lodges signed a Term of Free and Informed Consent (TCLE) and the Institution's Consent Term, which authorized the execution of the program. The project has noted all ethical concerns about research involving human beings contained in resolutions n. 466/2012 and 510/2016 of the National Health Council (CNS). This study was approved by the Research Ethics Committee (CEP) of the University of Amazonia (UNAMA), under opinion No. 2.909.500 and CAAE 94998418.7.0000.5173.

\subsection{Data Analysis}

As a methodology of data analysis, we used the content analysis of Bardin (2011), defined as a set of communication analysis techniques to obtain, through systematic procedures, the description of the content of the messages that allow the inference of conditions knowledge of the production of these messages.

\subsection{Study Population}

Ten elderly men, with a mean age of 62.7 years, participated in the extension program activities. An intentional sample was formed obeying the criteria of inclusion: being age 60 and over, of both genders and accepting to participate in the proposed activities. Elderly people with impaired mobility were excluded for the proposed activities and limitations of speech.

The team included 10 extension workers ( 8 nursing, 1 physiotherapy and 1 pharmacy) and the project coordinator (nurse). The actions were carried out at the ILPI Community Mission Belém in the North of Brazil, once a week, on Mondays, in the afternoon shift, lasting 3 hours. The elderly was submitted to approximately seven months of play activities that aimed at improving the autonomy of activities of daily living, stimulating attention, memory, identity recovery and interaction among the elderly. 


\section{RESULTS}

In view of this, following the phases of the PCA, the recognition phase was initially held, during which meetings were held to plan and discuss the methodologies that would be used in the ILPI. Subsequently, visits were made with the purpose of knowing the structure, the functioning of the institution and the elderly residents. Then, with the initiation of the ILPI visits, the disclosure phase was used to collect information from the elderly about what they liked to do, what they would like the group to bring to the institution, whether they had any illnesses and limitations.

Subsequently, the distribution phase began, through the application of the ludic activities during the meetings. Among the activities carried out are the domino championship, the game of the sequence, the dynamics of the present, the workshop of memory and joyful afternoon with songs and dances. It should be emphasized that the didactic materials used in each activity were carefully prepared by the extension agents, and each meeting required a specific type of material to the objective that was intended to be achieved.

The domino championship was the first activity used in the institution and aimed to promote moment of relaxation and interaction between academics and community residents. The domino is a game that most of the institution's elderly people practice, however, did not imagine how important this activity is to mental health, since it stimulates various abilities such as communication, attention skills, reasoning, concentration and coordination motor.

In the game of the sequence, initially, we delivered to the elderly cards and stickers of different colors, and then we present a poster with a pre-established sequence of colors. After that, the elders had to visualize the sequence for 1 minute, and then put the color patches according to the initial sequence presented, with the 5-minute tolerance to remember and reproduce the correct sequence. It is noteworthy that of the 10 elderly people who participated in the activity, only 1 managed to memorize and reproduce the correct sequence. In a second attempt, 5 were able to reproduce the sequence, however, they were unmotivated with the result of the first attempt.

On this same day, the dynamics of the present were also realized. To promote this dynamic, the elderly was placed on a wheel, then had to choose a certain color of card and write what they were feeling. Subsequently, each elder had to report their feeling to the group. This activity had as main objective to provide a wheel of conversation so that the elderly could interact, express their sad and happy feelings, and exchange ideas. It was observed that most of the elderly used this moment to express feelings of sadness, loneliness, mood swings and irritability.

In the memory workshop, 10 objects were placed inside a box, then one of the extensionists removed the objects and asked the elders to say their names to memorize the sequence. Subsequently, we offer the elderly, photos of the objects, asking them to put them in the correct sequence as shown at the beginning of the dynamic. In the first round of the workshop, of the 10 elderly participants, only 1 had the correct sequence, the others had difficulties in memorizing and organizing the sequence. At that, we held a second round, and this time the extensionists helped the elderly, so that they could get the sequence right. It was observed in the second round a greater motivation and effort of the elderly to increase their performance in developing their abilities to hit the correct sequence.

It is noteworthy that the ludic activities performed had the purpose of stimulating manual skills, motor coordination, attention, memory, concentration, perception and expression, as well as the promotion of social interaction among residents. In the course of the activities, it was noticed through the reports that the elders waited a lot for the meetings of the project and for the accomplishment of the activities, since they liked to interact and participate in the activities carried out by the academics, characterizing the 4th phase of the PCA, once that from these reports, the academics intensified the accomplishment of activities that could promote an active aging to the institutionalized elderly.

The elderly was motivated and available the activities proposed by the group, actively participating in all activities with enthusiasm. The proposed activities, elaborated and carried out at the ILPI, were in fact feasible to promote the health of the elderly, based on the postulates that base the strategies of play activities, considering the epidemiological and cultural reality of the elderly involved.

It was evidenced the importance of the transdisciplinary practice to improve the functional and cognitive autonomy of the elderly in the ILPI, demonstrated through the better social interaction and motivation for the accomplishment of daily life activities among the institutionalized elderly, despite having a heterogeneous profile. In this way, the proposal of intervention through play is necessary and urgent in order to obtain more independence, autonomy and quality in this phase of life.

During this time, it was sought to use several activities, in which the link between the academic and the elderly was established during the development of the project, being demonstrated by the frequent participation of the elderly in the activities, which provided the socialization and the creation of bonds friendship.

In making the Domino championship, the seniors were adept at choosing the competition partner and the tactics of the game. At the end of the championship was awarded the winner with a symbolic gift. The purpose of this activity was to promote fun among the elderly, in addition to stimulating communication, attention, concentration, motor coordination and logical reasoning skills.

\section{DISCUSSION}

\subsection{Influence of play games on improving the quality of life of the elderly}

During the domino championship, the verbal and nonverbal expressions of the elderly were represented by laughter, spontaneity, enthusiasm and motivation. At the end of the championship, the participants asked for more similar championships as it is a form of entertainment and a good distraction for them. In contrast to the findings of the present study, a similar survey of 85 elderly people from an LPAI in the northwest of Paraná, Brazil, found that the elderly perceived leisure activities as activities that 
Citation: Nathalie Porfirio Mendes et al., Interactive ludic Activities for Elderly Persons in a Long-Stay Institution. Australian Journal of Basic and Applied Sciences, 13(3): 41-45. DOI: 10.22587/ajbas.2019.13.3.6

filled their vacant time and had a positive impact on their activities (Derhun et al. 2018). Thus, table games are essential for the elderly, in addition to contributing to the exercise and stimulation of some skills necessary to improve the quality of life of the elderly (Olympio and Alvim, 2018).

However, during the sequencing and memory workshop, it was observed that the elderly presented negative self-perception regarding cognitive performance, since they spent more time in these activities, presented difficulties to complete the proposed action and expressed demotivation. Therefore, after performing these activities, the academics proposed to intensify the use of active methodologies that stimulate the improvement of cognitive function, such as attention, concentration, memory and reasoning. In addition, stimulation and cognitive training of the elderly should be encouraged, since stimulation influences cognitive performance and brings a significant improvement in the intellect of the elderly (Fernandes, 2014).

We observed in the dynamics of the present that, 10 elderly people participated in the activity, 4 wrote that they were sad and 6 wrote that they felt pain in some region of the body. Through this dynamic, the 4 elderly people who reported sadness showed feelings of loneliness and sadness due to the institutional environment they lived. However, after each activity and visit, it is evident that the emotional behavior improved, which was attributed to the reception that the extensionists provided, leaving them at ease to talk about their feelings (Guimarães; Barbosa and Gomes, 2017).

\subsection{Music and dance as a tool to promote the well-being of the elderly.}

During the activities, it was identified that there was a positive adaptation to the experiences involving music and dance, since the elderly showed an interest in participating, although, at that time, the elderly recognized their limitations. In this activity, there was an increase in self-esteem, joy and willingness to participate, which is believed to have a positive impact on the quality of life of these people. On this subject, a study carried out with 09 seniors at a LILO in Belo Horizonte, Brazil, identified, from the elderly 's report, that dance and music are the group' s preferred activities. In addition, such activities are fundamental to promote health and improve quality of life (Silva et al. 2016).

Another study carried out with 17 elderly individuals from a LIPI in the state of Goiás, Brazil, observed that leisure activities performed with institutionalized elderly favor learning and help strengthen interpersonal ties, provide a moment of leisure and physical well-being and provide cognitive maintenance and functional status (Cyrino et al. 2016). In addition, a study of 68 elderly people from a community center in Belo Horizonte concluded that play is a strategy that promotes improvements in the quality of life of institutionalized elders and is a means of strengthening autonomy (Fleurí et al. 2013).

The academics involved in the activities of this study shared and experienced the reality of an ILPI, putting into practice the principles of humanization. Through the proposed activities, the academics acted in a multiprofessional and transdisciplinary way, carrying out a care with responsibility, leadership, decision-making capacity and ethical conduct, having as a guiding principle the humanized care. Thus, it is interesting to emphasize the importance of the development of play activities, since the way the group worked, involving the elderly with their peculiar characteristics within a LTIPI, allowed the construction of a dynamic and interactive environment, leading to improvements for institutionalized people.

It was evidenced that play strategies are innovative technologies for gerontological appropriation, being configured as an adequate proposal to promote the health of the elderly, since they provide a climate of motivation, interaction, relaxation, interaction and creation of links (elderly, elderly-extension workers) and behavioral changes, thus constituting a facilitating tool for the care and promotion of active and healthy aging (Mendes et al. 2018), strengthening the premise that when creating a favorable and welcoming space allied to an innovative, differentiated and attractive technology, the possibility of people joining the proposed activities increases (Baños and Bosch, 2015).

The results found in the present study suggest that play methodologies should always be worked and valued, increasingly aiming at the implementation of these practices, considered as an important tool to promote the health of the elderly, thus providing biopsychosocial wellbeing, improve quality of life and promote healthy and active aging (Silva et al. 2017).

\section{CONCLUSION}

The elderly who participated in the proposed activities demonstrated satisfaction, motivation and a good interaction with the other elderly and the extension workers. Considering the proposal to strengthen interpersonal ties and provide a moment of relaxation, physical and mental well-being, it was observed that the proposed, elaborated and applied activities were effective in promoting the health and quality of life of the elderly.

It was evidenced that play activities are of great relevance for use with the elderly, and when used in ILPI are directly related to the health promotion of this population, providing benefits to the elderly. These benefits were evident during the performance of activities, such as interpersonal interaction, activation of cognitive abilities, joy and motivation. Therefore, the importance of the use of play strategies as a tool to promote improvements in the quality of life of institutionalized elderly people and the promotion of active and healthy aging should be reiterated.

The limitations of this study reside in the restricted sample of the elderly who benefited from the activities proposed by the extension project and in the short time dispensed the play activities and the duration of the research, which may limit the generalization of the findings in other scenarios. Therefore, it is hoped to encourage other groups to apply ludic strategies in the ILPI, with the affirmation that such methodologies help to promote the quality of life of institutionalized elders. Therefore, it is recommended that this strategy be carried out in other ILPI, thus suggesting a greater involvement of educational institutions with the elderly population, in order to disseminate practices to promote active and healthy aging. 


\section{REFERENCES}

Baños, J., E, and Bosch F. 2015. El empleo de películas comerciales en las facultades de medicina. Educación Médica. 16(4):206211. https://doi.org/10.1016/j.edumed.2015.09.

BARDIN, Laurence, 2011. Content analysis. 1 st. ed. São Paulo: Almedina.

Camarano A., A. 2016. Aging of the Brazilian population: a demographic contribution. In: Alcântara O, et al. National politics of the elderly: old and new issues. Rio de Janeiro: Ipea, p. 1-622.

Cyrino, R., S. Silva, L., E., D. Souza, M., R. Borges, C., J, and Pereira, T., S. 2016. ludic activities as strategy of health education with elderly people. Journal of Science in Extension. 12(3):154-163.

Costa, I., P. Costa, S., P. Pimenta, C., J., L. Lima, R., F, and Brito, M., J., M. 2017. The importance of ludic activities to the mental health of the institutionalized elderly: an experience report. In: II Brazilian Congress of health sciences.Campina Grande. Anais. Campina Grande: Cemep, p. $1-8$.

Derhun, F., M. Castro, V., C. Mariano, P., P. Baldissera, V., D., A, and Carreira, L. 2018. Perception of leisure among institutionalized elderly. Revista Baiana de Enfermagem. 32(25703):1-8. http://dx.doi.org/10.18471/rbe.v32.25703.

Fernandes, S., I., D. 2014. Cognitive stimulation in institutionalized elderly, M. S. thesis Dissertation, School of Education, Bragança, PA.

Fleurí, A., C., P. Almeida, A., C., S. Diniz, A., J. Magalhães, L., D., A. Ferreira, L., H., C. Horta, N., C. Prata, M., D., M, and Moura, R., D. 2013. Play activities with institutionalized elderly. Journal Nursing. 16(1):50-57.

Fuentes, S., A., M., P., S. Figueiredo, D. Mercadante, E., F. Lodovici, F., M., M, and Cerveny, C., M., O. 2014. The importance of empowering, and training, people working with the elderly in Day Centers. Revista Kairós Gerontologia. 17(3):233-251.

Guimarães, B., A. Barbosa, L., M., M., C, and Gomes, M., M. 2017. Promotion of mental health and cognitive stimulation in institutionalized elderly: experience report. New Hope Health Science Journal. 15(1):36-45.

Mendes, N., P. Costa, N., P. Campos, A., C., V. Polaro, S., H, and Golçalves, L., H., T. 2018. Socio-educational video debate technology for active aging promotion. Revista Anna Nery. 22(3):1-8. http://dx.doi.org/10.1590/2177-9465-ean-2017-0427.

Olympio, P., C., A., P, and Alvim, N., A., T. 2018. Board games: gerotechnology in nursing care practice. Revista Brasileira de Enfermagem. 71(2):818-826. http://dx.doi.org/10.1590/0034-7167-2017-0365.

Santos-Orlandi, A., A. Brito, T., R., P. Ottaviani, A., C. Rossetti, E., S. Zazzetta, M., S. Gratão, A., C., M. Orlandi, F., S, and Pvarini, S., C., L. 2017. Profile of older adults caring for other older adults in contexts of high social vulnerability. Anna Nery. 21(1):1-8.

Silva, M., R. Santos, N., P., V. Santos, R., A. Cunha, G., R, and Torres, L., M. 2016. The perception of the institutionalized elderly about the benefits of therapeutic workshops. Revista Brasileira em Promoção da Saúde. 29(Supl):76-84. http://dx.doi.org/10.5020/18061230.2016.sup.p76.

Silva M., R., F. 2016. Aging and social protection: approximations between Brazil, Latin America and Portugal. Social Service \& Society, pp: 215- 234.

Silva, W., Lucena, A., L., R. Araújo, M., J., A. Januário, D., C. Vieira, K., F., L, and Costa, R., R., A., B. 2017. Educational actions experienced with the elderly: an experience report. Revista de Ciência da Saúde Nova Esperança. 15(3):31-36.

Trentini M. Paim L, and Silva D., M., G. 2014. Convergent care research: a provocative design of changes in health practices. $3^{\mathrm{a}}$ ed. Florianópolis: Moriá, pp: 141 